\title{
Cisplatin-related Atrial Fibrillation during PEB Chemotherapy for Testicular Seminoma: A Case Report
}

Alessandro Pastorino*, Giacomo Bregni, Azzurra Damiani, Massimiliano Grassi, Alberto Puccini and Giuseppe Fornarini

Department of Medical Oncology, IRCCS AOU San Martino-IST, Genova, Italy

\begin{abstract}
Introduction: Cisplatin-related arrhythmias are not routinely described in the literature and their cardiac complications can lead to relevant hemodynamic events that could compromise the administration of chemotherapy and, above all, they could cause life threatening consequences.

Methods: A 37-year-old man with stage II B testicular seminoma was admitted to our department. The patient had a negative cardiologic history, blood count and chemistry were within normal limits except for hypomagnesaemia, and hence PEB chemotherapy was started. During cisplatin infusion, the patient experienced pulse arrhythmia with EKG diagnosis of atrial fibrillation.

Results: Despite the finding of atrial fibrillation, thanks to digoxin infusion and magnesium supplementation, chemotherapy was completed and on the next morning the heartbeat was rhythmical again.

Conclusion: One of the most important causes of arrhythmia is electrolytic imbalance and, for this reason, sodium, potassium, calcium, chlorine and magnesium plasmatic levels should be accurately checked before, during and after chemotherapy. In particular, magnesium seems to have a dominant role in the generation of arrhythmias during cisplatin-based chemotherapy because this antineoplastic compound increases ionic renal waste due to tubular damage. This case gives strength to the role of oral and intravenous electrolytes supplementation during platinumbased chemotherapy.
\end{abstract}

Keywords: Cisplatin-based chemotherapy; Atrial fibrillation; Arrhythmia; Hypomagnesemia; Testicular seminoma; PEB

Abbreviations: CP: Cisplatin; AF: Atrial Fibrillation; Mg: Magnesium

\section{Introduction}

Cardiac toxicity is one of the most challenging side effects related to antineoplastic agents. Even though there is large knowledge about acute and delayed cardiac consequences of some anticancer compounds such as anthracyclines or fluoropyrimidines, we still lack information about the arrhythmic potential of platinum derivatives. Chemotherapy induced cardiac arrhythmia is a major challenge for oncologists because of its unpredictability, lack of a clear mechanism of action and because it can lead, in some cases, to immediate life threatening consequences.

Cisplatin (CP) and its derivatives are the milestones for treatment of many solid tumors and their renal toxicity, myelosuppression, nausea, vomiting and neurotoxicity are well known but the arrhythmic potential is still a field of uncertainty and a point of debate. Cardiac events during CP infusion are infrequent and scientific information about these findings are lacking and mostly limited to case reports and case series $[1,2]$. Atrial fibrillation (AF), supraventricular tachycardia and bradycardia can be considered the most frequent. In particular, incidence rate of AF during cisplatin ranges from 4-6\% [3].

Here we report a case of AF during platinum-based chemotherapy drawing attention to the role of ions, particularly Magnesium $(\mathrm{Mg})$, in CP-related arrhythmias.

\section{Case Presentation}

In December 2015 a 37-year-old man was admitted to our department with diagnosis of stage II B testicular seminoma. The patient had no comorbidities, no allergies, no previous history of cardiologic disease, and an EKG performed before the hospitalization was completely negative. The baseline physical examination was normal and cardiac activity was rhythmical with no findings. The baseline post-operative CT-scan showed massive left para-aortic lymph-node involvement $(4.5 \mathrm{~cm})$ with concomitant left hydronephrosis, but no thoracic masses or para-cardiac metastases, ruling out potential mechanical reasons of arrhythmias.

The patient was started on PEB chemotherapy as follows: cisplatin $\left(20 \mathrm{mg} / \mathrm{m}^{2}\right)$ and etoposide $\left(100 \mathrm{mg} / \mathrm{m}^{2}\right)$ on days $1-5$ every 21 days, bleomicin $(30 \mathrm{mg})$ on day 2,9 and 16 of each cycle. Daily CP was preceded by a 60 -minutes fluid infusion composed by $1000 \mathrm{ml}$ of saline solution with $9 \mathrm{mEq}$ of potassium aspartate and $10 \mathrm{mEq}$ of $\mathrm{Mg}$ sulfate.

On day 1 blood count and biochemical profile were permissive for chemotherapy: WBC $7.75 \times 10^{9} / \mathrm{L}$ (n.v. $4.50-9.80 \times 10^{9} / \mathrm{L}$ ), RBC $4.5 \times$ $10^{12} / \mathrm{L}$ (n.v. $4.5-5.9 \times 10^{12} / \mathrm{L}$ ), platelets $248 \times 10^{9} / \mathrm{L}$ (n.v. $130-430 \times 10^{9} / \mathrm{L}$ ), INR 1.09 (n.v. $0.80-1.20$ ), GFR $85 \mathrm{~mL} / \mathrm{min}$, total bilirubin $0.52 \mathrm{mg} /$ dL (n.v. 0.20-1.20 mg/dL), sodium $135 \mathrm{mEq} / \mathrm{L}$ (n.v. $135-150 \mathrm{mEq} / \mathrm{L}$ ), potassium $3.5 \mathrm{mEq} / \mathrm{L}$ (n.v. $3.5-5.0 \mathrm{mEq} / \mathrm{L}$ ), chlorine $100 \mathrm{mEq} / \mathrm{L}$ (n.v. 90-120 mEq/L), calcium $8.9 \mathrm{mg} / \mathrm{dL}$ (n.v. 8.5-11.0 mg/dL ), ALT $17 \mathrm{U} / \mathrm{L}$ (n.v. 0-40 U/L), gGT $25 \mathrm{U} / \mathrm{L}$ (n.v. 11-50 U/L) but the Mg plasmatic concentration was slightly below the lower limit $(1.7 \mathrm{mg} / \mathrm{dL}$ vs. $1.9 \mathrm{mg} /$ dL). Despite this abnormal value, that was considered not clinically relevant, the first cycle of chemotherapy was started, supported by the

*Corresponding author: Alessandro Pastorino, Department of Medical Oncology IRCCS AOU San Martino-IST, Genova, Italy, Tel: +390105553301; E-mail: pastoale@alice.it

Received May 26, 2016; Accepted June 24, 2016; Published June 28, 2016

Citation: Pastorino A, Bregni G, Damiani A, Grassi M, Puccini A, et al. (2016) Cisplatin-related Atrial Fibrillation during PEB Chemotherapy for Testicular Seminoma: A Case Report. J Health Med Informat 7: 236. doi:10.4172/21577420.1000236

Copyright: @ 2016 Pastorino A, et al. This is an open-access article distributed under the terms of the Creative Commons Attribution License, which permits unrestricted use, distribution, and reproduction in any medium, provided the original author and source are credited. 
Citation: Pastorino A, Bregni G, Damiani A, Grassi M, Puccini A, et al. (2016) Cisplatin-related Atrial Fibrillation during PEB Chemotherapy for Testicular Seminoma: A Case Report. J Health Med Informat 7: 236. doi:10.4172/2157-7420.1000236

fact that Mg would be infused together with the saline solution before chemotherapy. On the morning of the third day of chemotherapy, during CP and before the etoposide infusion, the patient experienced palpitations and dry cough. The physical examination revealed pulse arrhythmia that was confirmed by EKG diagnosis of AF with normal ventricular rate of $86 \mathrm{bpm}$ with no signs of myocardial damage (Figure 1). After cardiologic consult, based upon the normal ventricular rate and on the curative goal of chemotherapy in testicular seminoma, we decided to continue the infusion of $\mathrm{CP}$ and etoposide with the addition of low molecular weight heparin at a therapeutic dose (enoxaparin 6000 I.U. twice daily). On the evening of the same day pulse was still arrhythmic and heart rate increased to $110 \mathrm{bpm}$; hence, digoxin $0.5 \mathrm{mg}$ in $250 \mathrm{ml}$ of simple saline solution in a 12-hour continuous infusion was started. The next morning EKG revealed a normal heart rate at $90 \mathrm{bpm}$ (Figure 2), and sodium, potassium, $\mathrm{Mg}$, calcium and chlorine were within normal limits. Hence the pre-planned schedule of PEB was completed with no other cardiac events Prophylactic oral $\mathrm{Mg}$ supplementation was started since the third day of chemotherapy and the patient was discharged with daily oral beta-blocker and low molecular weight heparin with prophylactic intent (enoxaparin 6000 I.U. once a day). During the next two PEB cycles $\mathrm{Mg}$ levels were within normal ranges excpet the last day of the third cycle when the patient had hypomagnesemia due to stopping oral supplementation by patient's spontaneous choice (Figure 3).

\section{Discussion}

In our case report the patient was young, had a negative cardiologic history, normal renal function despite left hydronephrosis and no clinical signs of ventricular pump dysfunction. Serum Mg concentration of $1.7 \mathrm{mg} / \mathrm{dL}$ was the only parameter slightly below the normal limit, and it was wrongly considered as "not clinically relevant" in such a fit and young patient. CP was considered the main cause of AF for several reasons: its arrhythmic potential, the closely temporal link between the onset of AF and CP infusion, the lower arrhythmic action of etoposide and bleomicin whose plasmatic half-lives are about 1.5 and 2 hours with an elimination time of 11 and 24 hours, respectively. Moreover the low baseline $\mathrm{Mg}$ plasmatic concentration and the potential $\mathrm{Mg}$ renal waste induced by $\mathrm{CP}$ during the first two days of chemotherapy may be other elements causing AF in a 37-year old fit patient. We identify CP as the most likely cause of improved renal $\mathrm{Mg}$ loss but it is still an open point of debate whether the heart rate normalised thanks to digoxin or $\mathrm{Mg}$ subministration. In fact digoxin and $\mathrm{Mg}$ supplementation have two different mechanisms of action in stopping atrial fibrillation: Digoxin acts by slowing down heart rate with its negative chronotropic effect while $\mathrm{Mg}$ reconstitutes cell surface ionic aequilibrium that we consider the most likely cause of chemotherapy-related arrhythmias. The mechanism of action causing CP-related arrhythmias, and generalizable to all antineoplastic agents, can be explained by two pathways: 1) The direct toxic damage on myocardial cells and 2) The

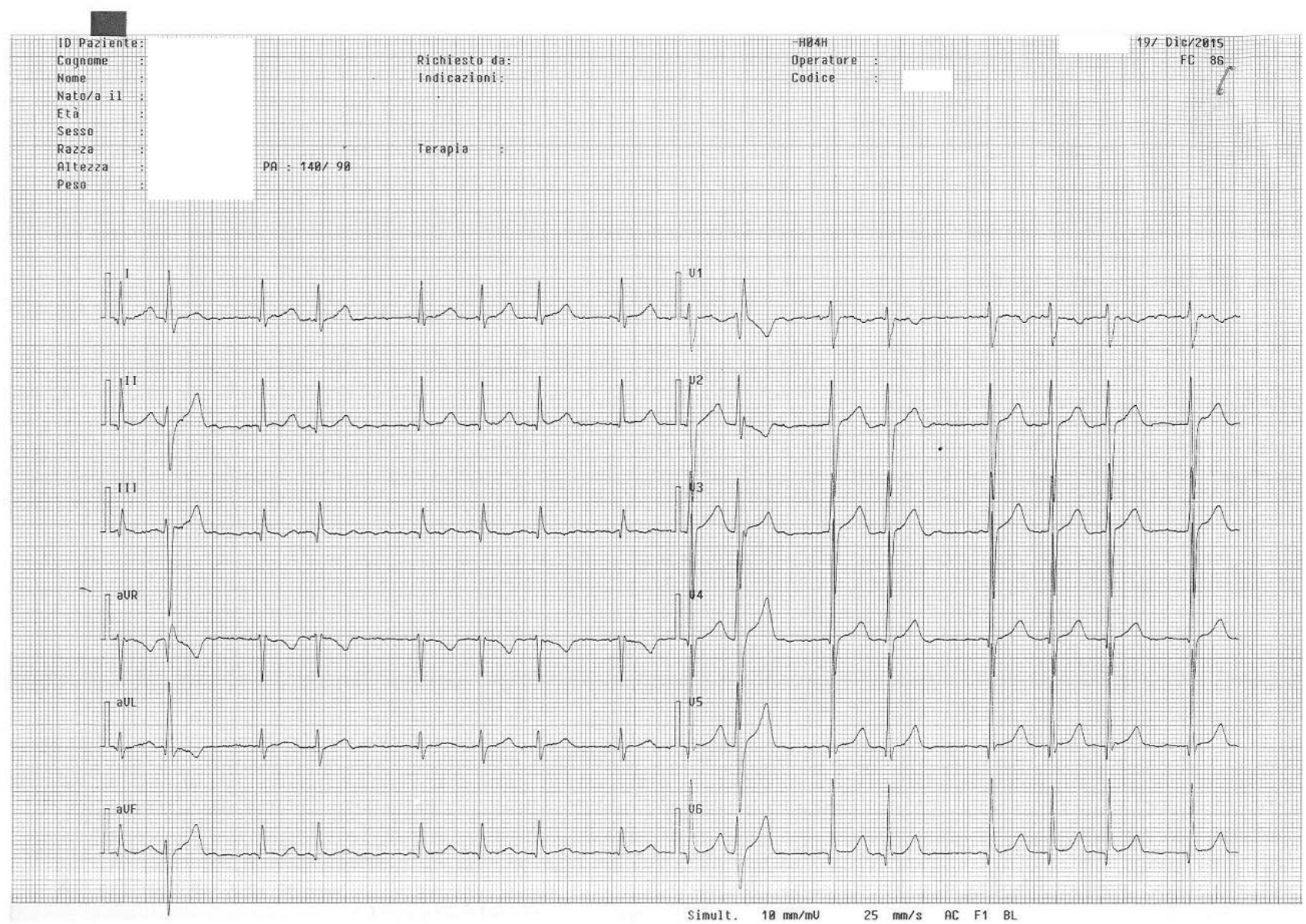

Figure 1: EKG on the morning of the $3^{\text {rd }}$ day of chemotherapy: AF with normal ventricular response. 
Citation: Pastorino A, Bregni G, Damiani A, Grassi M, Puccini A, et al. (2016) Cisplatin-related Atrial Fibrillation during PEB Chemotherapy for Testicular Seminoma: A Case Report. J Health Med Informat 7: 236. doi:10.4172/2157-7420.1000236

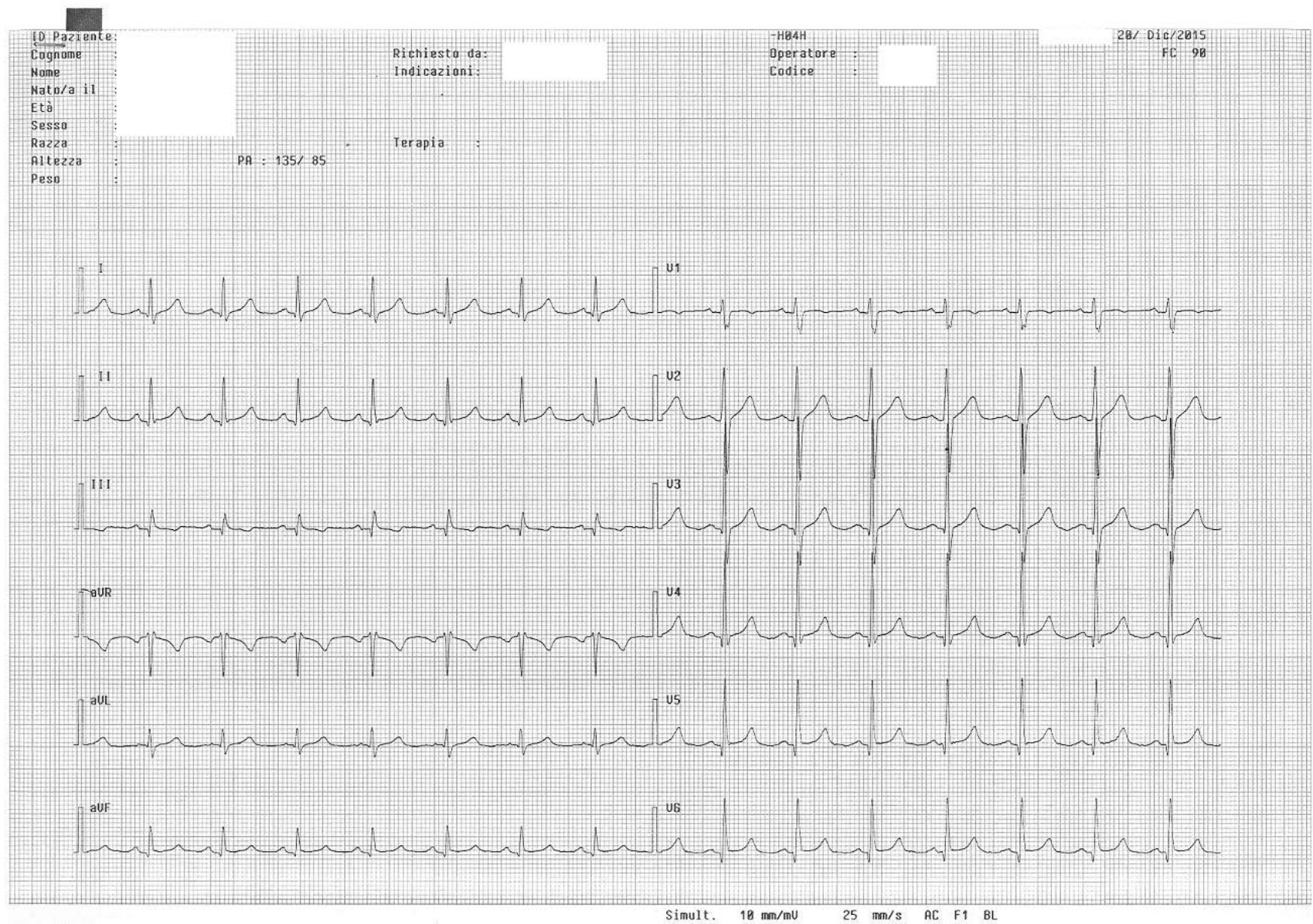

Figure 2: EKG on the morning of the $4^{\text {th }}$ day, after 12-hours digoxin infusion and $\mathrm{Mg}$ oral supplementation: normal morphology.

consequent ionic disequilibrium deriving from cell injury.

The second point is the most fascinating and interesting mechanism of $\mathrm{CP}$ induced arrhythmias since it is very well known that the ionic equilibrium is the key for cellular action potential. Starting from this point it is quite complicated to find a clear correlation between $\mathrm{Mg}$ serum level and arrhythmias because $\mathrm{Mg}$ concentration is strictly linked to potassium and other cations' plasma levels. Specifically $\mathrm{Mg}$ is involved in the activation of $\mathrm{Na} / \mathrm{K}$ ATPase cell pump that is the major player in the maintenance of membrane action potential. Moreover, $\mathrm{Mg}$ is an intracellular cation and we can only measure its plasmatic concentration because erythrocyte $\mathrm{Mg}$ concentration measurement by spectrophotometry is not routinely available.

Several old experiences supporting the correlation between $\mathrm{CP}$ and $\mathrm{Mg}$ metabolism have been published. During CP-based chemotherapy plasma concentrations of $\mathrm{Mg}$, potassium and calcium were shown to be strongly reduced in association with higher renal excretion rate of these cations [4]. Shilsky et al. studied the renal wasting of $\mathrm{Mg}$ and found that 23 of 44 patients treated with CP developed hypomagnesemia with two cases of hospitalization [5]. The long-term effect of CP on $\mathrm{Mg}$ equilibrium was confirmed by Bell who documented a chronic hypomagnesemia requiring oral supplementation at 6 weeks after $\mathrm{CP}$ infusion [6]. The data from these experiences were supported by another publication that confirmed the role of $\mathrm{CP}$ in generating $\mathrm{Mg}$ deficit and renal loss probably due to direct $\mathrm{CP}$-induced renal tubular damage [7]. Another single center experience stated that intracellular $\mathrm{Mg}$ concentration begun to decrease on the first day of $\mathrm{CP}$ infusion and persisted until the fourth day, with a normal plasmatic level of Mg: this could be explained by an initial Mg shift from the cell into the plasma with a consequent intracellular Mg depletion [8]. This finding supports the concept that plasma $\mathrm{Mg}$ levels are not representative of real $\mathrm{Mg}$ intracellular concentration.

In particular, in this case report, tha patient had AF despite $\mathrm{Mg}$ was diluted in saline solution infused before every daily CP-based chemotherapy. This could be explained by the fact that the patient, starting from a basal hypomagnesemia, had inadequate $\mathrm{Mg}$ storage and the infusion of $\mathrm{Mg}$ before chemotherapy was not able to balance $\mathrm{Mg}$ renal waste caused by daily cisplatin. In addiction to this hypothesis we confirm the concept that $\mathrm{Mg}$ aequilibrium is strictly connected to the balance of the other ions $(\mathrm{Na}, \mathrm{K}, \mathrm{Cl})$ and its kinetics should be considered in correlation with these others cations and anions and not in its own right: This add a further level of complexity to our discussion

The importance of $\mathrm{Mg}$ on the onset of atrial and ventricular arrhythmias has been investigated in a meta-analysis of seventeen randomized trials: the administration of $\mathrm{Mg}$ with prophylactic intent reduced the incidence of AF by $29 \%$ and of ventricular arrhythmias by $48 \%$ after cardiac surgery [9]. Moreover Mg infusion has an important role during arrhythmias because it is able to slow sinus node rate and prolong atrial-ventricular node refractoriness by decreasing calcium cellular input. 
Citation: Pastorino A, Bregni G, Damiani A, Grassi M, Puccini A, et al. (2016) Cisplatin-related Atrial Fibrillation during PEB Chemotherapy for Testicular Seminoma: A Case Report. J Health Med Informat 7: 236. doi:10.4172/2157-7420.1000236

\section{$\mathrm{mg} / \mathrm{dL}$}

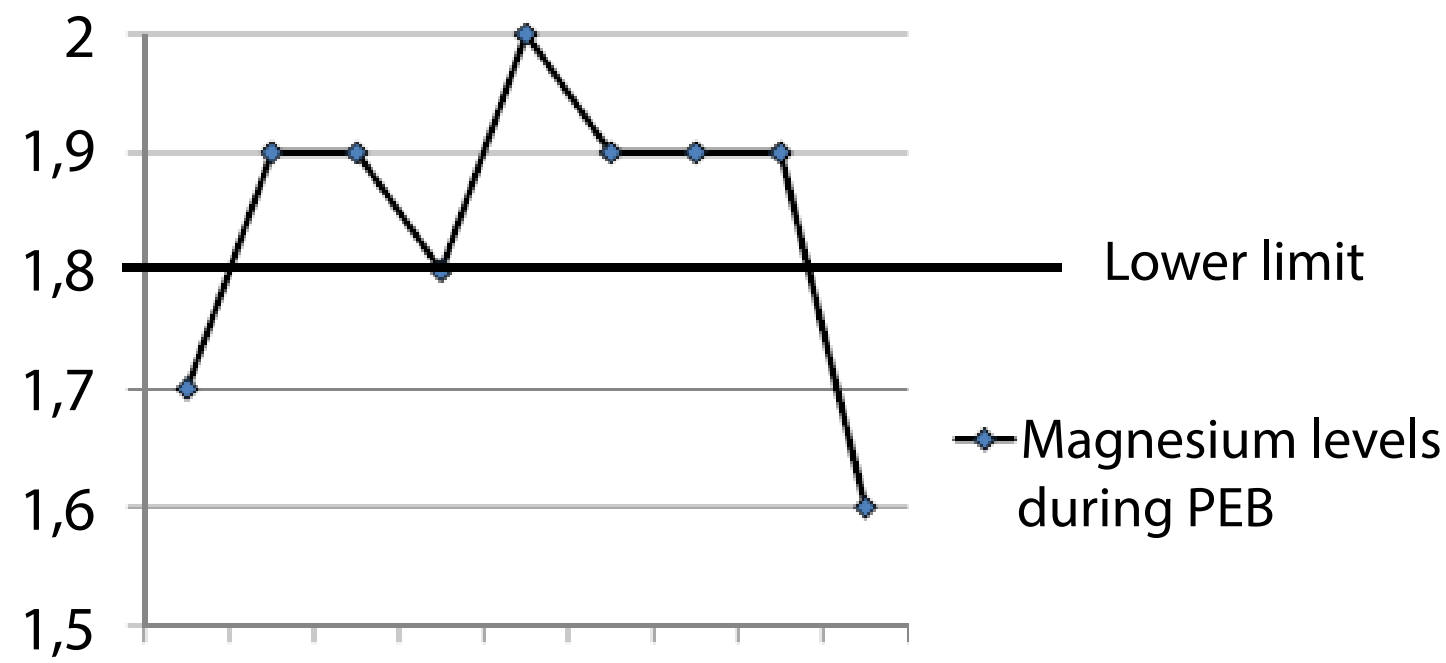

\section{1st PEB 2nd PEB 3rd PEB}

Figure 3: Magnesium plasmatic level during the three cycles of chemotherapy. $1.8 \mathrm{mg} / \mathrm{dL}$ is the cut-off value for plasmatic hypomagnesaemia.

Howeverthe role of $\mathrm{Mg}$ as the only actor in generating cardiac arrhythmias is still a point of debate since $\mathrm{Mg}$ depletion is strictly connected with renal wasting of potassium and both electrolytes are involved in the electrical equilibrium of cellular membrane [10].

From this unusual and challenging experience we can learn some lessons and draw a few conclusions for daily clinical practice:

1) Arrhythmic potential of chemotherapy is still a field of research needing attention on potential triggering events (baseline ionic alterations, ionic disorders due to diarrhea or vomiting and past cardiac problems in patients' clinical histories).

2) Plasmatic ions levels ( $\mathrm{Mg}$, sodium, potassium, calcium and chlorine) are important and when electrolytes are not within normal limits may be recommended to delay chemotherapy until ions levels come back to the correct range (with or without medical intervention).

4) When laboratory tests show a normal plasmatic ionic concentration intracellular storage may be different, especially if the patient had had diarrhea and vomiting.

5) We recommend $\mathrm{Mg}$ supplementation for CP-based chemotherapy because it is usually well tolerated by all patients; it can be started before chemotherapy and it should last for all the duration of chemotherapy even if $\mathrm{Mg}$ serum levels are normal since the plasmatic $\mathrm{Mg}$ concentration may be not totally representative of real intracellular Mg storage.

\section{Consent for Publication}

Written informed consent for the publication of this manuscript was obtained by the patient who allowed us the use of his clinical data for scientific purpose.

\section{References}

1. Tassinari D, Sartori S, Drudi G, Panzini I, Gianni L, et al. (1997) Cardiac arrhythmias after cisplatin infusion: three case reports and a review of the literature. Ann Oncol 8: 1263-1267.

2. Menard O, Martinet $Y$, Lamy $P$ (1991) Cisplatin-induced atrial fibrillation. J Clin Oncol 9: 192-193.

3. Guglin M, Aljayeh M, Saiyad S, Ali R, Curtis AB (2009) Introducing a new entity: chemotherapy-induced arrhythmia. Europace 11: 1579-1586.

4. Zumkley RK, Bertram HP, Preusser P, Kellinghaus H, Straub C, et al. (1982) Renal excretion of magnesium and trace elements during cisplatin treatment. Clin Nephrol 17: 254-257.

5. Shilsky RL, Anderson T (1979) Hypomagnesemia and renal magnesium wasting in patients receiving cisplatin. Ann Intern Med 90: 929-931.

6. Bell DR, Woods RL, Levi JA (1985) Cis-diammine-dichloreplatinum-induced hypomagnesemia and renal magnesium wasting. Eur J Cancer Clin Oncol 21: 287-290.

7. Buckley JE, Clark VL, Meyer TJ, Pearlman NW (1984) Hypomagnesaemia after cisplatin combination chemotherapy. Arch Intern Med 144: 2347-2348.

8. Sartori S, Nielsen I, Tassinari D, Rigolin F, Arcudi D, et al. (1993) Changes in intracellular magnesium concentrations during cisplatin chemotherapy. Oncology 50: 230-234.

9. Shiga T, Wajima Z, Inoue T, Ogawa R (2004) Magnesium prophylaxis for arrhythmias after cardiac surgery: a meta-analysis of randomized controlled trials. Am J Med 117: 325-333.

10. Iseri LT, Ginkel ML, Allen BJ (1991-1992) Magnesium-potassium interactions in cardiac arrhythmia. Examples of ionic medicine. Magnes Trace Elem 10 193-204. 